\title{
Drill pipe monitoring of vortex-induced vibration during IODP Expedition 332 observatory installations ${ }^{1}$
}

Kazuya Kitada, ${ }^{2,3}$ Eiichiro Araki, ${ }^{2}$ Toshinori Kimura, ${ }^{2}$ Masataka Kinoshita, ${ }^{2}$ Achim Kopf, ${ }^{2}$ Sebastian Hammerschmidt, ${ }^{2}$ Sean Toczko, ${ }^{2}$ Tomokazu Saruhashi, ${ }^{4}$ Ikuo Sawada, ${ }^{4}$ Masanori Kyo, ${ }^{4}$ Yasuhiro Namba, ${ }^{4}$ Yukari Kido, ${ }^{2}$ Demian M. Saffer, ${ }^{2}$ Rachel Lauer, ${ }^{2}$ and Geoff Wheat ${ }^{2}$

\section{Chapter contents}

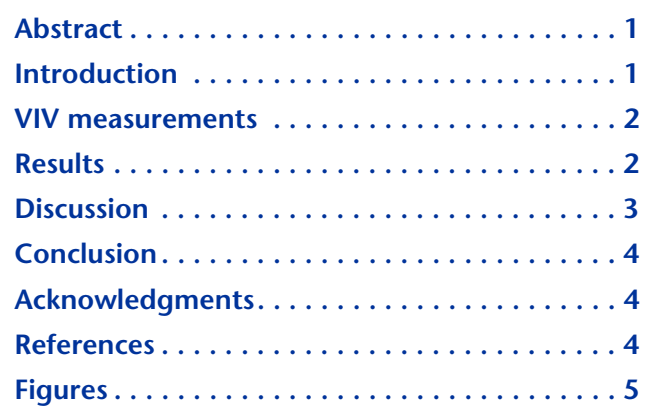

${ }^{1}$ Kitada, K., Araki, E., Kimura, T., Kinoshita, M., Kopf, A., Hammerschmidt, S., Toczko, S., Saruhashi, T., Sawada, I., Kyo, M., Namba, Y., Kido, Y., Saffer, D.M., Lauer, R., and Wheat, G., 2011. Drill pipe monitoring of vortex-induced vibration during IODP Expedition 332 observatory installations. In Kopf, A., Araki, E., Toczko, S., and the Expedition 332 Scientists, Proc. IODP, 332: Tokyo (Integrated Ocean Drilling Program Management International, Inc.). doi:10.2204/iodp.proc.332.106.2011

'Expedition 332 Scientists' addresses. ${ }^{3}$ Correspondence author: kkitada@jamstec.go.jp ${ }^{4}$ Center for Deep Earth Exploration, Japan Agency for Marine-Earth Science and Technology, 3173-25 Showa-machi, Kanazawa-ku, Yokohama, Kanagawa 236-0001, Japan.

\section{Abstract}

This study reports on vortex-induced vibration (VIV) suppression methods for long-term borehole monitoring system (LTBMS) installation in areas of strong ocean currents such as the Kuroshio Current. One of the primary challenges in installing the LTBMS was to deploy high-precision, sensitive sensors into the borehole without damaging them during their trip through the water column. Two field tests were performed using accelerometers attached to the instrument carrier and/or drill pipes to collect data on the characteristics and effects of drill pipe VIV. These tests demonstrated that vortex suppression can be achieved by using drill collars and attaching ropes to the drill pipe. Therefore, these methods were applied to the drill pipe (above the sensor assembly) for the actual recovery and installation of the observatory systems during the Integrated Ocean Drilling Program (IODP) Expedition 332. From the observations and data collected over a period of several days of VIV monitoring during the LTBMS installation and SmartPlug retrieval, the following three points can be made regarding VIV suppression: (1) the bottom-hole assembly should be lowered in the low-current area, with the relative current speed being as low as possible, (2) the drifting speed should be kept well below $1 \mathrm{kt}$, and (3) the drifting angle between drifting direction and sea current should be kept as small as possible (definitely $<45^{\circ}$ ). The results of VIV monitoring during Expedition 332 attest that the amplitude was further reduced to $<0.5 \mathrm{~g}$, eventually contributing to the success of the first LTBMS installation at IODP Site C0002.

\section{Introduction}

The Nankai Trough, where the Philippine Sea plate subducts beneath the Eurasian plate off southwest Japan, is one of the most active earthquake zones in the world (Fig. F1). As part of the Nankai Trough Seismogenic Zone Experiment (NanTroSEIZE), a series of long-term borehole monitoring systems (LTBMS) that combine elements of circulation obviation retrofit kits (CORKs) (e.g., Ocean Drilling Program [ODP] Leg 196 [Mikada, Moore, Taira, Becker, Moore, and Klaus, 2005]) and 'neath seafloor equipment for recording Earth's internal deformation (NEREID) (ODP Leg 186 [Suyehiro, Sacks, Acton, and Oda, 2003]) to investigate fault mechanics and seismogenesis along subduction megathrusts are being installed into three holes along the NanTroSEIZE transect offshore the Kii Peninsula. 
The Kuroshio Current, one of the world's fastest ocean currents, can flow at $>5 \mathrm{kt}$ in the Nankai Trough area. When the drill pipe is placed in a strong current, an asymmetrical flow pattern caused by the unsteady separation of flow over bluff bodies (e.g., the vertical drill pipe in the water column), creates alternating vortices (Karman vortex) on the downstream side of the drill pipe. These vortices then create periodic lateral forces on the drill string, causing it to vibrate, which is known as vortex-induced vibration (VIV).

During Integrated Ocean Drilling Program (IODP) Expedition 319 (Saffer, McNeill, Byrne, Araki, Toczko, Eguchi, Takahashi, and the Expedition 319 Scientists, 2010), a field test simulating the future planned deployment of the LTBMS was run into the hole to investigate two main objectives: (1) to evaluate environmental conditions and their effects on the LTBMS sensors for their development (Kimura et al., 2011), such as shock, acceleration, and vibration during installation; and (2) to confirm sensor installation operational procedures, such as onboard assembly of the sensor tree, ship maneuvers to reenter the sensor tree, and entry into the hole. During these tests, VIV effects on the sensor carrier and associated sensors were extremely severe, damaging or destroying the sensors sensitive internal components and cracking the sensor carrier itself (Saffer, McNeill, Byrne, Araki, Toczko, Eguchi, Takahashi, and the Expedition 319 Scientists, 2010).

A second phase of field tests was conducted during the D/V Chikyu's March 2010 CK10-01 cruise to examine VIV suppression/countermeasures (Kitada et al., 2011). Four accelerometers were attached to the drill pipes and instrument carrier to collect VIV data at separate points along the test string. VIV reduction ropes (24 mm outside diameter [OD]), using the drill collars as a heavy mass weight, and the newly redesigned instrument carrier were tested to establish the VIV reduction method for the LTBMS installation. The possibility of using 5 inch drill pipes and $3 \frac{1}{2}$ inch tubing for the bottom-hole assembly (BHA) inside the borehole was also explored.

VIV can be controlled by various passive methods (Blevins, 1990; Kwon et al., 2002) (e.g., streamlined fairings are one kind of effective device in general use for VIV suppression [Miyazaki et al., 2008]). Here we show acceleration data on drill pipe VIV collected during IODP Expedition 332 (Kopf et al., 2010). First, we evaluate the characteristics and causes of the vibration on drill pipe in order to suppress VIV. Then, we establish the installation method of the LTBMS in strong current areas such as the Nankai Trough. Finally, the operation procedure is verified and further modification points are discussed.

\section{VIV measurements}

A self-recording triaxial accelerometer $(94 \mathrm{~mm}$ diameter and $760 \mathrm{~mm}$ length) powered by internal lithium batteries and with a 2 GB SD memory card was attached to the $5 \frac{1}{2}$ inch drill pipes at the bottom of the assembly and near the sea surface through the attachment tool before running into the hole (Fig. F2). The accelerometer measures acceleration in three axes $(x, y$, and $z)$ at a sampling rate of $250 \mathrm{~Hz}$, where the $z$-axis corresponds to the downward direction of the drill pipe (Fig. F2). A special frame was designed to secure the accelerometer to the drill pipe, with a copper sheet set between the attachment blocks and the drill pipe to prevent slipping or rotation during deployment. Self-locking nuts were used to prevent the bolts from loosening because of vibration.

During Expedition 332, acceleration measurements were recorded to monitor VIV on the drill pipe during the SmartPlug recovery at IODP Site C0010 and the LTBMS installation at IODP Site C0002 (Kopf et al., 2010). The BHA was made up and run in the hole while the Chikyu was in the low-current area (LCA) (current $<\sim 1.5 \mathrm{kt}$ ), upstream and northwest ( $\sim 30$ miles away) of Site C0010. Two accelerometers were attached to the drill pipe (Fig. F3) while running the BHA into the water; one was attached just above the BHA and the other was attached near the sea surface. After the completion string was lowered to $1700 \mathrm{~m}$ drilling depth below rig floor (DRF), drifting to the target site began at a speed of $\sim 1$ kt (Fig. F4). Acceleration data were collected during the entire operation and downloaded when the instruments were recovered on deck.

\section{Results}

\section{SmartPlug retrieval at Site $\mathrm{C0010}$}

Acceleration data from drill pipe VIV during SmartPlug recovery at Site C0010, along with current, drifting speed, and course data during retrieval, are plotted in Figure F4. Two types of acceleration are observed in the data. One type is VIV, correlated with drifting speed and angle between drifting direction and sea current direction. The methodology of attaching ropes (24 $\mathrm{mm} \mathrm{OD)}$ to the drill string from $1200 \mathrm{~m} \mathrm{DRF}$ to the surface successfully reduced acceleration from VIV to $<1 \mathrm{~g}$. The second type is due to shock transmitted to the drill string by contact with the rotary table while running pipe (Fig. F4); the peak-to-peak amplitudes of these accelerations were close to $1.5 \mathrm{~g}$.

Peak-to-peak amplitude reached $6 \mathrm{~g}$ (as recorded by the accelerometer near the rotary table), with greater acceleration in the horizontal direction when lowering 
drill pipes began. This contrasted with peak-to-peak amplitudes recorded during recovering drill pipe, where the horizontal acceleration reached $0.5 \mathrm{~g}$. Two other acceleration events (shocks) were recorded during Site C0010 reentry (>2.5 g) and SmartPlug recovery (Fig. F4).

\section{LTBMS installation at Site $\mathbf{C 0 0 2}$}

The LTBMS CORK assembly deployment began in the LCA $(<1 \mathrm{kt})$, with Accelerometer 1 attached just above the CORK head running tool and Accelerometer 2 attached at $1720 \mathrm{~m}$ DRF (Fig. F3). To reduce VIV while drifting to Site C0002, the Chikyu's drifting speed was set at $\sim 0.5 \mathrm{kt}$ and the angle between drifting direction and sea current was set to be $<45^{\circ}$. Drifting toward the site began at $0830 \mathrm{~h}$ on 6 December 2010, arriving at Site C0002 at $0045 \mathrm{~h}$ on 8 December (Fig. F5).

A large set of acceleration data was collected during the LTBMS installation, and the full data set is shown in Figure F5. These results show that VIV amplitude was reduced to $<0.5 \mathrm{~g}$, whereas the amplitude of the vertical component of the acceleration was $<0.2 \mathrm{~g}$ during drifting.

Two kinds of vibrations affecting the drill pipe are identified from the acceleration data. One is VIV, a direct result of the effects of the sea current, drifting speed, and angle between the Chikyu's course and the current. VIV was successfully reduced to $<0.5 \mathrm{~g}$ by attaching ropes (24 $\mathrm{mm}$ OD) to the upper section of the drill string. The second kind of vibrations originate from the drill string contacting the rotary table while running pipe and striking the wellhead during reentry, and depending on the strength of impact, may reach larger magnitudes than that originating from VIV (Fig. F5). One new component observed during LTBMS deployment was acceleration originating from the remotely operated vehicle (ROV) connecting to the CORK head and landing on the ROV platform; maximum peak-to-peak acceleration amplitudes of some of these events were close to $6 \mathrm{~g}$.

\section{Discussion}

Dramatic reductions in VIV are clearly demonstrated by the simple expedient of attaching lengths of ropes $(24 \mathrm{~mm} \mathrm{OD})$ to the upper part of the drill string where strong ocean currents (e.g., the Kuroshio Current) have the greatest impact on the drill string. During preliminary field tests using the Chikyu (Japan Agency for Marine-Earth Science and Technology Cruise CK10-01) and the newly redesigned sensor carrier, ropes were attached to the bottom section of the BHA to simulate electrical cables to be used in the final design (Kitada et al., 2011).
Analysis found that an unexpected side effect of adding the simulated cables was a reduction in VIV, presumably through the disruption of vortex formation by breaking up the current flow around the drill pipe.

Expanding on these field tests, laboratory tests confirmed the vortex dampening by rope-attachment to the drill string (Kyo et al., 2011). During SmartPlug retrieval and LTBMS installation during Expedition 332 , the ropes were also attached along the drill pipe just above the BHA (Fig. F3), which reduced the amplitude of VIV to $<0.5 \mathrm{~g}$ (Figs. F4, F5). Attaching ropes along the drill pipe is effective for VIV suppression, especially when comparing with results from the dummy run test during IODP Expedition 319 (Fig. F6) (see also Saffer, McNeill, Byrne, Araki, Toczko, Eguchi, Takahashi, and the Expedition 319 Scientists, 2010). This method has other significant advantages, being simple and easy to apply and low cost, with no maintenance requirements, especially when compared with more traditional vortex suppression steel devices by Blevins (1990).

One key factor in managing VIV is careful planning and control of the ship's drift during deployment through the current. Acceleration data collected during SmartPlug recovery showed that managing drifting speed was crucial for reducing VIV compared to the actual speed of the current (Fig. F4). However, the difference in angle between drifting direction and the sea current direction remains an important factor for VIV suppression. This was illustrated by the sudden drifting direction changes while moving to the LCA during SmartPlug recovery operations; when the difference in angle increased, amplitude of VIV also increased (Fig. F4). The results of VIV monitoring showed that VIV was further suppressed with a drifting speed $<1 \mathrm{kt}$ and a drifting angle $<45^{\circ}$ during LTBMS installation at Site C0002 (Fig. F5).

In the shallow part of the Kuroshio Current $(<300$ $500 \mathrm{~m}$ depth), the current speed can reach $>3 \mathrm{kt}$. This can have considerable negative effects on LTBMS, or more generally observatory instrument installation and/or recovery procedures and the integrity of the component sensors themselves. To mitigate these effects, the LTBMS sensor assembly was first lowered to $1700 \mathrm{~m}$ DRF in the LCA $(<1 \mathrm{kt})$ before drifting to Site $\mathrm{C0002}$ began. These procedures increase the amount of operation time needed for deployment ( 2 days in this installation). However, when considering the strong current (maximum near $6 \mathrm{kt}$ ) (Fig. F4), the time lost is a small price to pay for reducing VIV and maintaining the integrity of the CORK structure and instruments.

Another factor in VIV generation and suppression is resonance of the drill pipe. VIV reduction in this case 
focuses on reducing the tendency for the natural frequency of the drill pipe coinciding with the frequency of vortex shedding. Applying a heavy mass to the drill string, in this case by adding drill collars to the sensor assembly, can help to reduce this source of VIV. Data from the field test performed during the Chikyu Cruise CK10-11 shows VIV suppression, especially at high frequency (Kitada et al., 2011); however, more work remains to more carefully quantify VIV suppression using drill collars.

One additional source of concern-unrelated to VIV-are the sudden accelerations observed when the drill string and BHA impact the wellhead and the rotary table while running pipe. With maximum peak-to-peak amplitudes reaching $6 \mathrm{~g}$, special care needs to be taken to prevent damaging the delicate sensors comprising the LTBMS assembly.

\section{Conclusion}

The successful LTBMS installation proves the validity of the various methods and techniques developed to minimize VIV and impact shock damage to the sensor assembly. Results from the field test conducted during Expedition 319 (Saffer, McNeill, Byrne, Araki, Toczko, Eguchi, Takahashi, and the Expedition 319 Scientists, 2010) showed that the structural design of the sensor carrier required a complete redesign. A new H-beam type instrument carrier was developed for the sensor tree assembly and adding drill collars to balance the BHA were discussed. VIV monitoring of different assemblies run in the Kuroshio Current, along with tests conducted on land, helped confirm the value of VIV suppression by adding ropes to the drill string and drill collar counterweights. The key points learned from these operations are as follows: (1) the BHA should be lowered in the LCA, with the relative current speed being as low as possible, (2) the drifting speed should be kept well below $1 \mathrm{kt}$, and (3) the drifting angle between drifting direction and sea current should be kept as small as possible (definitely $<45^{\circ}$ ). These helped Expedition 332 successfully install one of the most complex CORK assemblies yet attempted, more remarkable in light of the relative inexperience in these operations on the part of the Chikyu.

\section{Acknowledgments}

This research used data provided by the Integrated Ocean Drilling Program (IODP). We would like to thank all who assisted in the collection of the acceleration data during the Chikyu cruises by the Center for Deep Earth Exploration-Japan Agency for MarineEarth Science and Technology, including the captains, offshore installation managers, operations superintendents, ship crews, and scientists.

\section{References}

Blevins, R.D., 1990. Flow Induced Vibration: New York (Van Nostrand Reinhold).

Kimura, T., Araki, E., Takayama, H., Kitada, K., Namba, Y., Kinoshita, M., and Kyo, M., 2011. The development and evaluation of sensors for long-term borehole monitoring system. Underwater Technol. Symp., 2011. doi:10.1109/UT.2011.5774128

Kitada, K., Araki, E., Kimura, T., Saruhashi, T., Kyo, M., Sawada, I., and Namba, Y., 2011. Vortex induced vibration suppression of the drill pipe for the long-term borehole monitoring system installation. Underwater Technol. Symp., 2011. doi:10.1109/UT.2011.5774131

Kopf, A., Araki, E., and Toczko, S., 2010. NanTroSEIZE Stage 2: riserless observatory. IODP Sci. Prosp., 332. doi:10.2204/iodp.sp.332.2010

Kwon, S.H., Cho, J.W., Park J.S., and Choi, H.S., 2002. The effects of drag reduction by ribbons attached to cylindrical pipes. Ocean Eng., 29(15):1945-1958. doi:10.1016/S0029-8018(02)00010-0

Kyo, M., Saruhashi, T., Sawada, I., Namba, Y., Araki, E., Kitada, K., and Kimura, T., 2011. Plan and technological difficulties on NanTroSEIZE long term borehole monitoring system. Underwater Technol. Symp., 2011. doi:10.1109/UT.2011.5774151

Mikada, H., Moore, G.F., Taira, A., Becker, K., Moore, J.C., and Klaus, A. (Eds.), 2005. Proc. ODP, Sci. Results, 190/ 196: College Station, TX (Ocean Drilling Program). doi:10.2973/odp.proc.sr.190196.2005

Miyazaki, E., Ozaki, M., Nishioka, S., and Minamiura, J., 2008. Application of riser fairings to the D/V "Chikyu" during drilling in high current area. Oceans TechnoOcean Jt. Conf., 2008. doi:10.1109/OCEANSKOBE.2008.4530990

Saffer, D., McNeill, L., Byrne, T., Araki, E., Toczko, S., Eguchi, N., Takahashi, K., and the Expedition 319 Scientists, 2010. Proc. IODP, 319: Tokyo (Integrated Ocean Drilling Program management International, Inc.). doi:10.2204/iodp.proc.319.2010

Suyehiro, K., Sacks, I.S., Acton, G.D., and Oda, M. (Eds.), 2003. Proc. ODP, Sci. Results, 186: College Station, TX (Ocean Drilling Program). doi:10.2973/ odp.proc.sr.186.2003

Wessel, P., and Smith, W.H.F., 1998. New, improved version of Generic Mapping Tools released. Eos, Trans. Am. Geophys. Union, 79(47):579. doi:10.1029/98E000426

Publication: 11 December 2011

MS 332-106 
Figure F1. Ship tracks over the bathymetric map around Sites C0002 and C0010 in the Nankai Trough. Red line = ship tracks during SmartPlug retrieval, blue line = ship tracks during long-term borehole monitoring system (LTBMS) installation. Inset shows location of adjacent regions. The GMT software package (Wessel and Smith, 1998) was used to generate the maps.

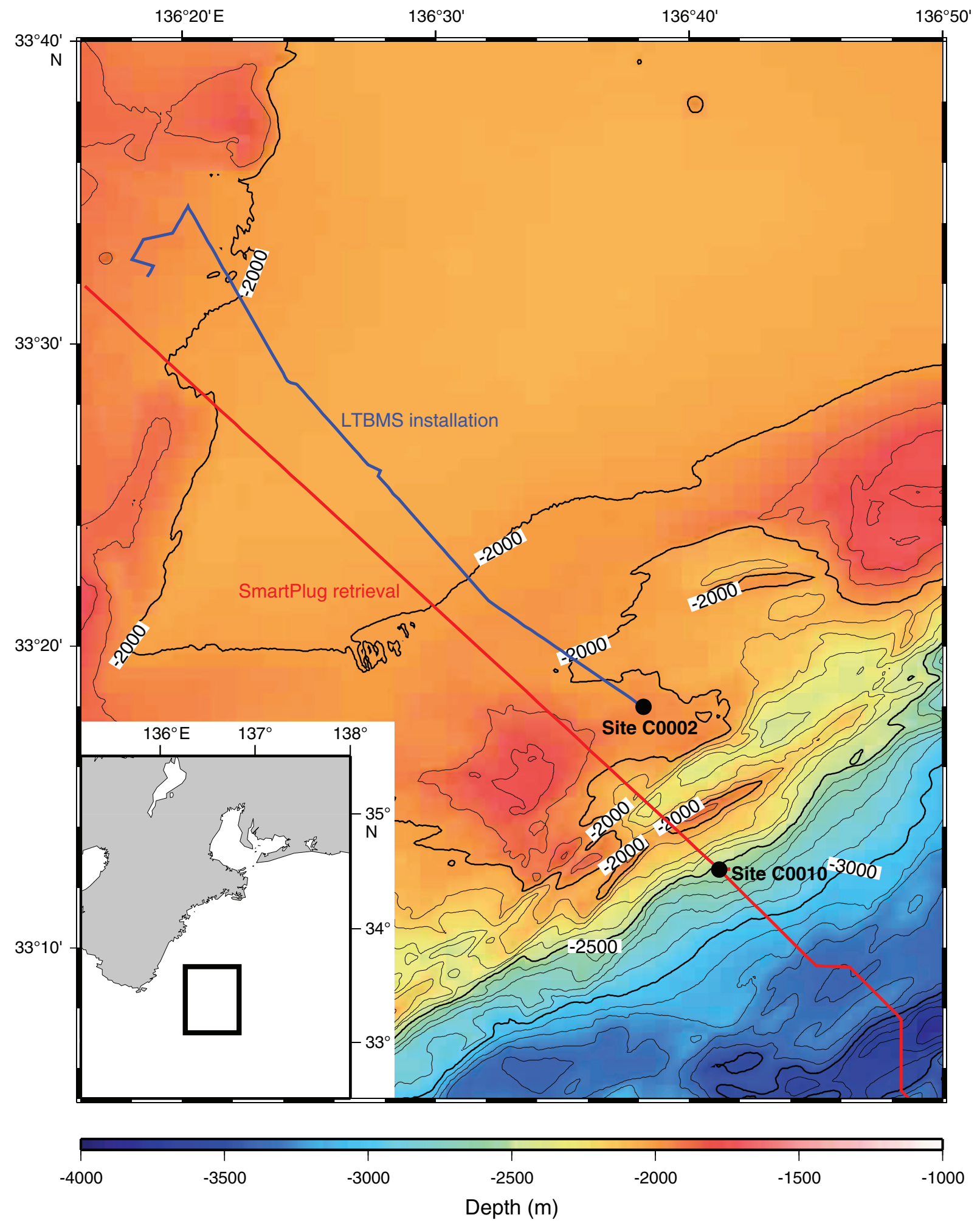


Figure F2. (A) Schematic drawing and (B) photograph of accelerometer package attached for VIV measurements. Red arrows on accelerometer show the orientation of the three aces. BHA = bottom-hole assembly.

A

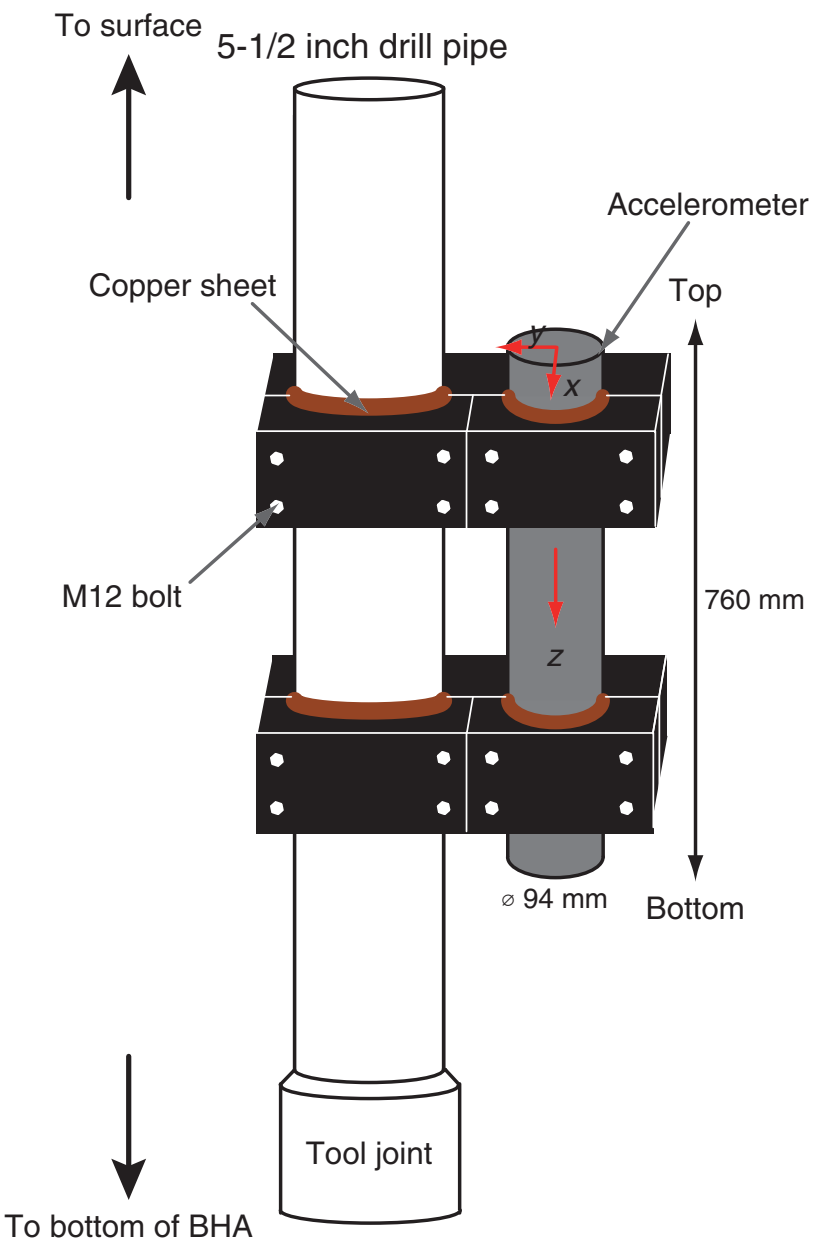

B

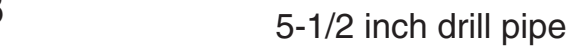


Figure F3. Bottom-hole assemblies for (A) SmartPlug retrieval and (B) long-term borehole monitoring system (LTBMS) installation, Expedition 332. The depth of attached accelerometers (ACC) and the sections where vortex-induced vibration (VIV) ropes were attached, are shown. CORK = circulation obviation retrofit kit.

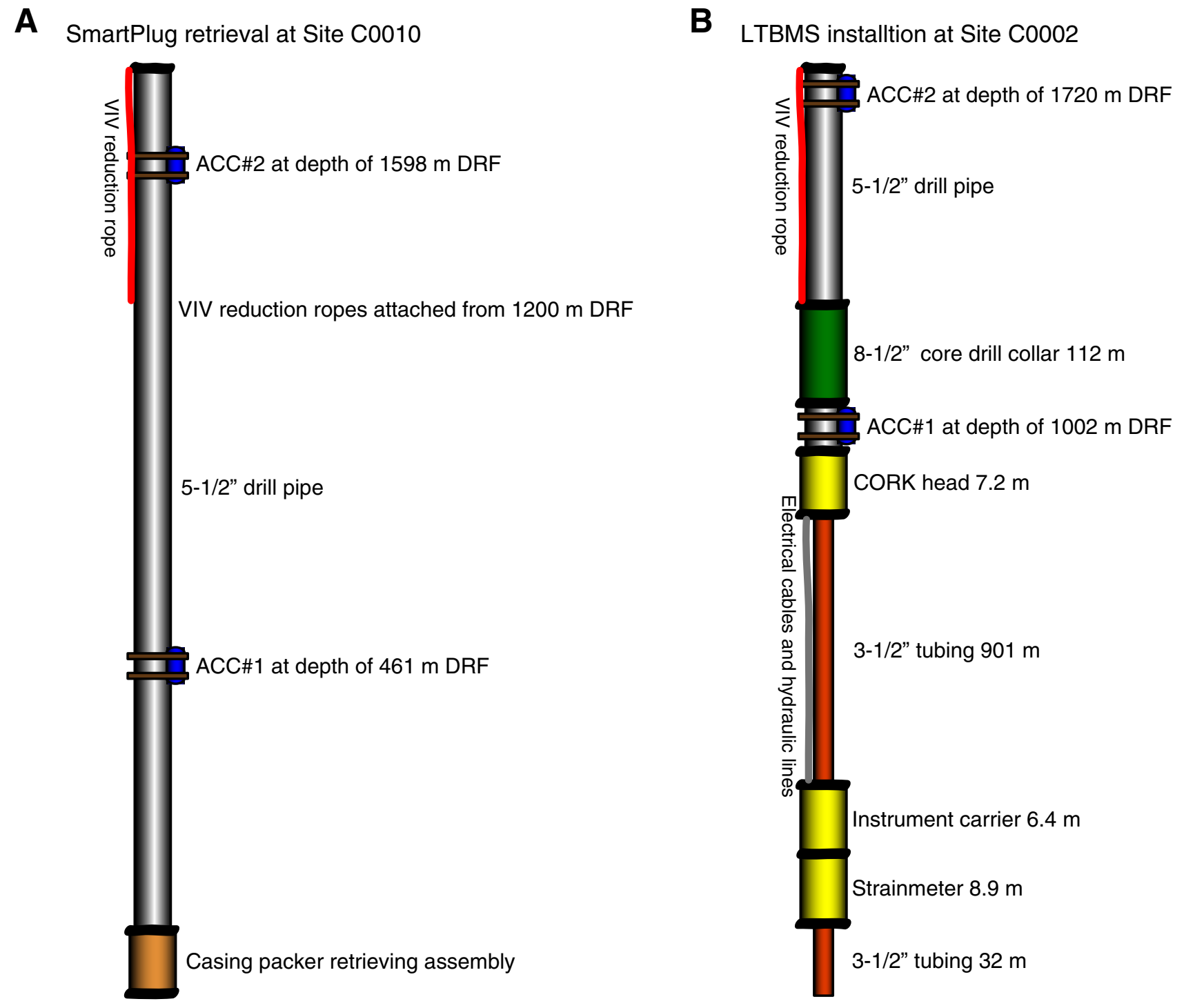


Figure F4. Results of VIV measurements collected from Accelerometer 1 at $461 \mathrm{~m}$ DRF during SmartPlug retrieval at Site C0010. The top plot shows the current and drifting speeds. The second plot shows the current and the drifting directions as well as the difference in angle between the current direction and the drifting direction. The bottom three plots show $x, y$, and $z$ components of the acceleration data versus time. Yellow shaded area $=$ period during drifting to Site $\mathrm{C} 0010$ and LCA. $\mathrm{POOH}=$ pull out of hole.

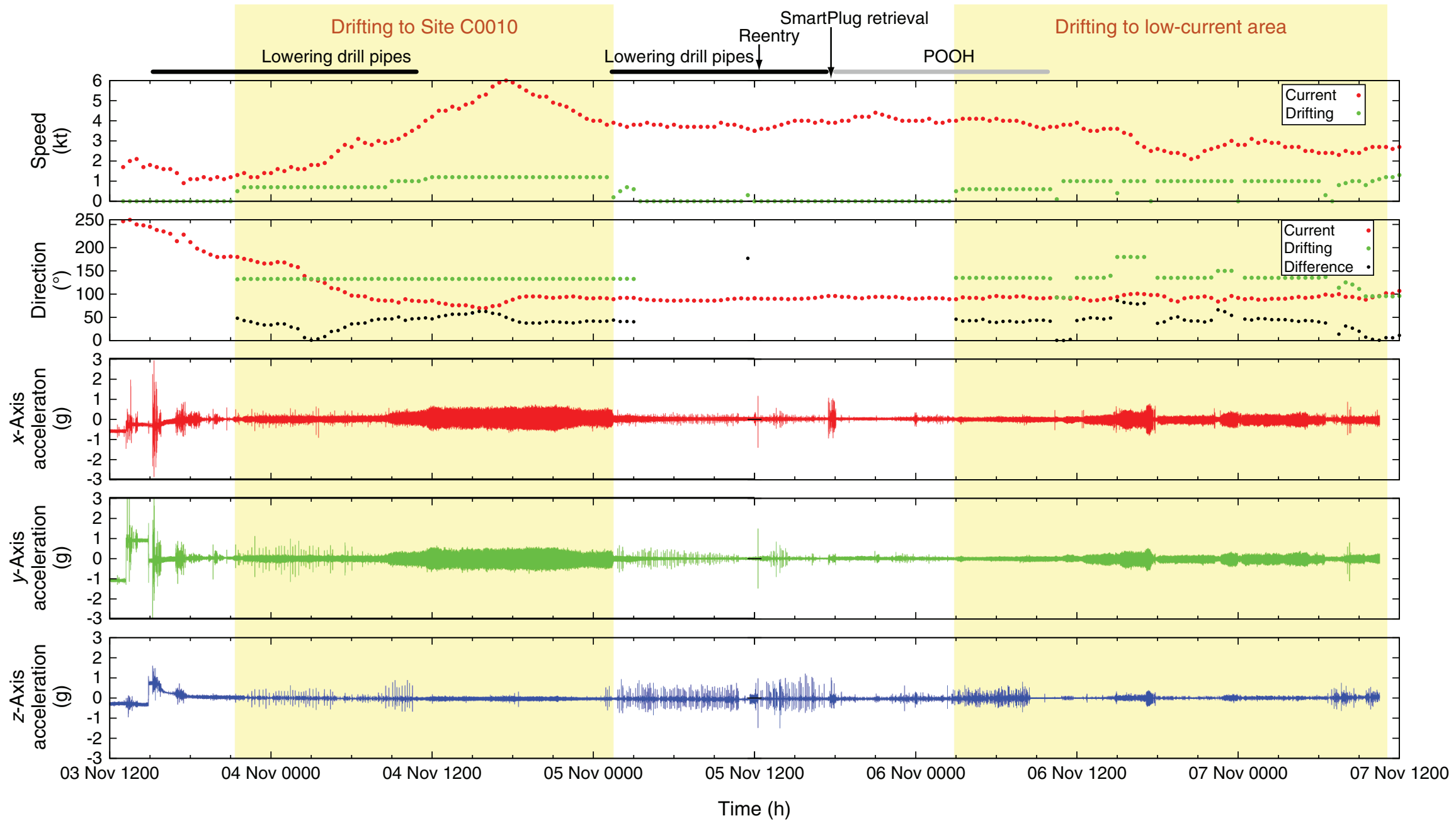


Figure F5. Results of VIV measurement collected from Accelerometer 1 at $1002 \mathrm{~m}$ DRF during LTBMS installation at Site C0002. The plots show $x, y$, and $z$ components of the acceleration data versus time. Yellow shaded area = period during the drifting to Site C0002 and LCA, blue shading $=$ period during which the remotely operated vehicle $(\mathrm{ROV})$ was connected to the sensor package. $\mathrm{POOH}=$ pull out of hole.

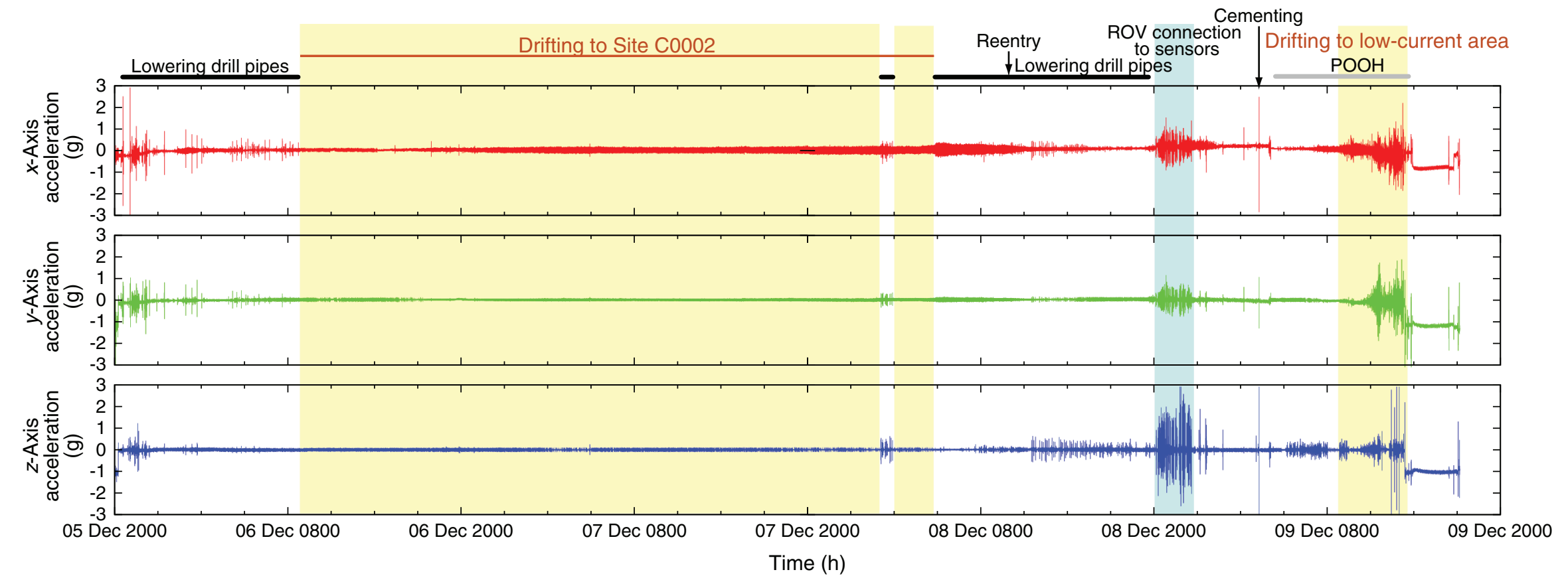


Figure F6. Results of VIV measurements during the dummy run test, Expedition 319 (see Saffer, McNeill, Byrne, Araki, Toczko, Eguchi, Takahashi, and the Expedition 319 Scientists, 2010). The plots show $x, y$, and $z$ components of the acceleration data versus time. Yellow shaded area = period during drifting to Site C0010.

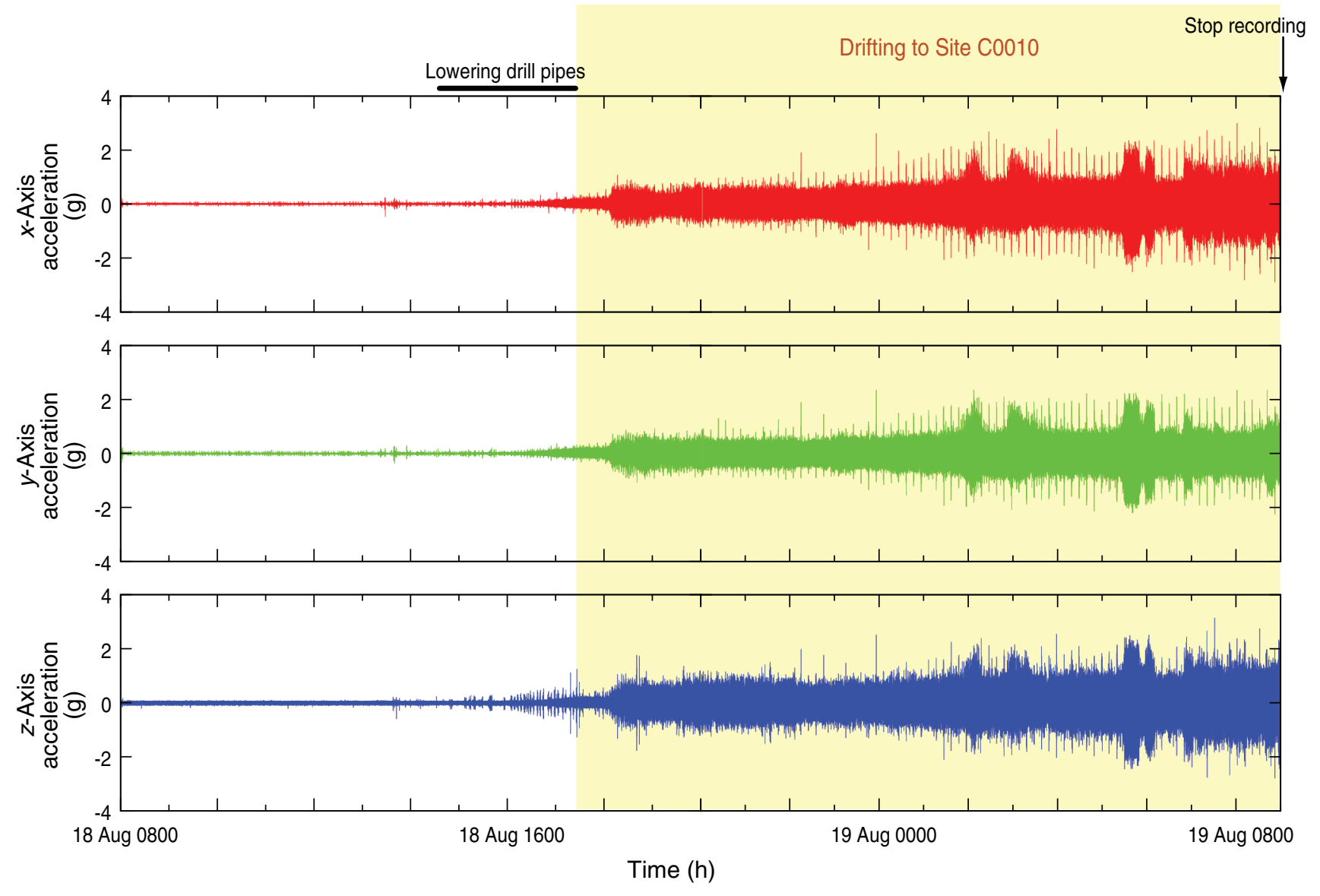

